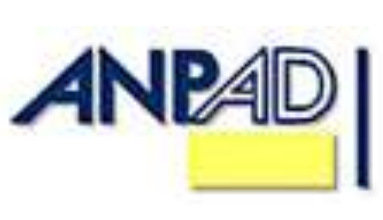
Available online at
http://www.anpad.org.br/bar
BAR, Rio de Janeiro, v. 12, n. 4, art. 2, pp. 348-364, Oct./Dec. 2015 http://dx.doi.org/10.1590/1807-7692bar2015150019

\title{
How Can We Define Mastery? Reflections on Learning, Embodiment and Professional Identity
}

Marina Dantas Figueiredo Universidade de Fortaleza - UNIFOR/PPGA

Ana Sílvia Rocha Ipiranga Universidade Estadual do Ceará - UECE/PPGA

Received 23 April 2015; received in revised form 3 November 2015; accepted 6 November 2015; published online 15 December 2015. 


\begin{abstract}
In this article we reflect upon the knowledge production process through the body in the social-material arrangement of craft. Resorting to the embodiment paradigm, we aim to theoretically understand how someone reaches the mastery that characterizes the domain of craft skill. In analogy with craft practices, we analyze how knowledge that relies under practical performances such as skill are built and kept through the bodily relation with the making of things in the immediate contact with the world. At the end, we conclude that such reflections about mastery may be useful to investigations on professional identity.
\end{abstract}

Key words: skill; embodiment; phenomenology; learning process; identity. 


\section{Introduction}

This article aims to foster a reflection on the corporal knowledge-production process in the socialmaterial arrangement of craft. Falling back upon phenomenology to explain the learning experience as a result of the perception of the living body, we seek to theoretically understand how one achieves the so-called mastery related to craftwork know-how. As mastery can be defined as practical proficiency, or as the embodied comprehension of a practical knowledge, we focus on the way how skill constitutes and maintains itself through the bodily relation that someone achieves while performing practices with high levels of proficiency. The objective of this paper, though, is to develop a theoretical background to analyze the kind of practical know-how, such as mastery, that relies on some embodied features of its practitioners to build professional identities.

The intended contribution to the field of Organization Studies (OS) is to theoretically reinforce the concept of mastery as a way to understand skill as resulting from knowledge embodiment. In this respect, even though practice-based studies on OS have privileged the analysis of knowledge embodiment as lived experience, the lack of concrete references to the cultural context where it takes place ends up making most of those studies describe such processes in a superficial way (Sandberg \& Dall'Alba, 2009). While traditional ontology takes the principle of detachment - meaning people are essentially detached from the world, but get connected to it as they perform and experience many practical activities during the process of living in the world - a phenomenological perspective such as the one we take in this article considers that the entwinement of the person with the world is the defining condition of being.

Within craft, mastery relates to a way of being that rises from practice, during the embodiment process of a skill. Being a master craftsperson refers to the social identity of someone due to the skills that this person has learned with his/her body while performing such practice. Departing from that, we can achieve the understanding that the person who embodies a skill not only has the knowledge that describes his/her professional formation, as the embodiment of a skill changes the whole person, transforming him/her into a skillful body. We understand that the enduring contact of someone with a certain kind of practical knowledge is a defining experience, in such a way that professional and personal identities are never separable and both cannot exist beyond the context of practices regarding this profession.

As we intend to discuss professional identity taking craft as a powerful example and/or object of reflection, considerations on professions and professionalization are also necessary. Professions are understood as occupations with special attributes, where cognitive dimension is centered on a certain body of knowledge and techniques and on the training necessary to master such knowledge (Larson, 1977). In a modern perspective, professions are closely connected to social structure (Parsons, 1939) and to an ideal of work that has been developed in the West, particularly after the Industrial Revolution. If in the pre-modern period professions would be considered as a matter of tradition (Sennett, 2008), modern professions depend on practical and intellectual institutions that legitimate structures of authority and competence, such as universities (Jackson, 1970). The professional environment, understood as an institutional environment, has deep implications on the process of embodiment of professional know-how and the forge of professional identity.

However, the idea of identity that we support in this paper has no connection to the performance of social actions, as we want to show that the embodiment of professional identity goes beyond learning the cognitive and normative features of a certain kind of work. To accomplish this we briefly examine the field of sociology of professions, beyond the bureaucratic tendencies of its traditional approaches (Klegon, 1978; Parsons, 1939), in order to clarify how professional practices shape ways of being in the world that goes way outside the limits of occupational tasks performed by social actors within an

institutional framework. Notwithstanding how the discussions within the sociology of professions field develop in the background of modern paradigms, we turn to craft as an illustration of a pre-modern or a non-modern profession that can be analyzed through the lenses of post-modern theories as a 
phenomenology and embodiment paradigm to help to explain how the forge of professional identity is a matter of becoming. More than a profession, craftsmanship is a way of life that seems to have been waned with the advent of industrial society, but - as Sennett (2008, p. 9) states "Craftsmanship cuts a far wider swath than skilled manual labor; it serves the computer programmer, the doctor, and the artist".

It is worth mentioning that we could have chosen the word craftsmanship as a synonym of mastery, as we understand their meanings to actually be really close. So we can highlight that the word craftsmanship connects the substantive craftsman/craftsperson with the suffix -ship, meaning certain status, domain or specific condition that defines a state or condition of being. Relying on that, the intended meaning for the word mastery in this article is one that designates the very own condition of being a master of something. What we want to express through the idea of mastery is the practical domain of a skill, or a mastery that we carry in our bodies and that is refractory to formulation in terms of any system of mental rules and representations. Such skill is acquired not only through formal instruction, in an institutional arena, but also and mainly by routinely carrying out specific tasks involving characteristic postures and gestures in the natural setting of such practice. It also relates to the total field of relations constituted by the presence of the organism-person, indissoluble body and mind, in a richly structured environment (Ingold, 2000).

To achieve the objective of this article, we also need to define (even though in a superficial way) craft among the vast array of human achievements. Initially it may be necessary to shed light on the usages of the word craft and to choose the one that seems to be more appropriate to the considerations about mastery that we want to make here. After all, craft entangles different meanings, shifting from an artistic expression to a range of extremely practical activities, as well as to a system of production. Even though the word craft may have enough representative potential to comprise these and other ideas, we start from a relatively stable definition, which states that craft is a set of knowledge and skills that may be used in a practical way, in order to produce something, usually an object, according to a preformulated aim (Adamson, 2007; Becker, 1978; Risatti, 2007). Such aim is rooted in a craft's traditions and in the desire to perform a purposeful work that are both constituent parts of the master's identity, meaning something he/she deeply understands as an essential part of his/her performance, and also an essential part of him/herself.

In the following sections, we hope to clarify some of the abstract ideas that we have just outlined. The article is structured as follows. First, we define know-how from a phenomenological standpoint to highlight the embodiment paradigm (Csordas, 1990) as an emergent issue for practice-based theories on learning within the field of OS. Next, we delve into the work of the skillful craftsperson in order to connect the idea of someone's embodiment of a skill with the formation of professional identity. Then, we bring up the discussion of previously presented ideas, followed by a brief conclusion that clarifies the intended contributions of this paper and indicates the applicability of the ideas that we have discussed in future empirical studies.

\section{An Embodied Approach on Know-how}

The embodiment paradigm (Csordas, 1990) opens up possibilities for understanding culture as embodied experience. As a result, it also allows investigations on how the world constitutes people as selves (Hancock, 2008). Traditionally, studies that take the embodiment perspective have flourished in the anthropological field following two main streams. Firstly, one that approaches the body as a resource for the metaphors that constitute culture (Csordas, 1990). Secondly, one that takes the body within the ongoing process of adaptation to culture (Kleinman \& Kleinman, 1991).

According to the assumptions of both streams, many studies - more or less related to the embodiment paradigm or to a phenomenological perspective - have developed emphasis on two specific issues. The first one, more related to the first stream, highlights that body movements are the generating principle of a way of somatic knowledge (Ness, 1992; Reed, 1998; Sheets-Johnstone, 1990; Sklar, 1994). 
The second one, more related to the second stream, elaborates the understanding that perception rises from a bodily and embodied pre-reflexive knowledge, and that cognition rests upon the environment as a consequence of a process of active engagement (Csordas, 1990; Ingold, 2000; Merleau-Ponty, 2012).

Studies that address the issue of body movement state that somatic knowledge is a resource for embodied communication. They understand that body movement itself produces an authentic way of knowledge that is just as laden with the meanings that people need to accomplish their existences as any other form of knowledge, for example the ones that enable verbal communication (Sklar, 1994). It means that people express their own selves and recognize each other's selves through the habits they accumulate in their bodies as much as with verbalizing words. After all, both are ways of communicating. According to Greiner (2008), many theories that intend to decipher spatial images of the body - such as posture schemas, images of the self, images of the body and of otherness - stem from the idea that the body has a communicative potential in itself. The understanding of the insides and the outsides of the body is conceived as a relationship between the information that comes from the outside and the feelings that are part of inner processes.

Two points deserve our close attention regarding studies that take body movement as a specific way of knowledge. The first point is that the way through which they understand perception depends on the in-and-out of body flux of certain cognitive processes. These processes impose that the body must be a vehicle for experience and a processor for knowledge, which only becomes clear when it reaches a person's conscience. Extending on this point, it is worth mentioning the work of neuroscientists such as Lakoff and Johnson (1999) and Llinás (2002), who stated that thought is the inner expression of movement. As thought rises from movements, the process of knowing and recognizing the things of the world starts from the sensorimotor system. For Lakoff and Johnson (1980), for example, this is how the metaphors of thought get organized, i.e. the way through which people conceptualize the world and themselves starting from their own bodily experiences.

The second point is that, as these studies seek to recognize a common basis for embodied ways of knowledge within body movement, they tend to get close to an understanding that takes the body as a semantic platform (Sheets-Johnstone, 1990), in a textual way that borders the semiotic paradigm. According to this, the living body is perceived as a kind semantic model that rises from action (Greiner, 2008). Concepts are generated or soar to conscience in the body through actions, and in turn, these concepts also lead to actions. Action feeds back concepts, and concepts feeds back actions in a retroactive cycle. Movement, as a sort of link with meaning, is what gives support to the continuous flux of information between the body and the environment. The way that movement gets ordered in time and space is also the way that the images of the body are built in the flux inside the body (images that begin with thoughts) and outside the body (images that turn into actions), as such images organize themselves in latent embodied processes of communication. Thus, conscience encloses an abstract meaning that comes from the environment via embodiment, which means to say that knowledge comes from outside and then becomes part of the body.

It may remind us of how Mauss (1973) described the acquisition process of a skill (in his own words, a body technic) as a result of a sort of learning that mirrors the social-cultural environment to produce changes in the body. For Mauss (1973), the embodiment process of a body technique is a way of acquisition, inflected by the formalism of the technique. In his own words, "every technique properly so called has its form" and "for every technique there is an apprenticeship" (p. 475). Thus, the embodied behavior is consequence of the individual's psychological adaptation, and it is moreover ruled out by formal education or at least by circumstances of collective life.

Relying on this, Mauss (1973) classifies body techniques according to modes of transmission of body techniques, taking embodied learning processes as a synonym of training (indoctrination) and as a socially elaborated way of body conditioning. Beginning with such understanding of body as an instrument, and from the idea of embodiment as training, we can reach the very important notion of dexterity. The meaning of dexterity is frequently mixed up with ability (skill), but Mauss (1973) points out that, by specifically using this word, he wants to refer precisely to physical capabilities. The quotation below may clarify this idea. 
This is the place for the notion of dexterity, so important in psychology, as well as in sociology. But in French we only have the poor term 'habile' which is a bad translation of the Latin word 'habilis', far better designating those people with a sense of the adaptation of all their wellcoordinated movements to a goal, who are practised, who 'know what they are up to'. The English notions of 'craft' or 'cleverness' (skill, presence of mind and habit combined) imply competence at something. Once again we are clearly in the technical domain (Mauss, 1973, p. 78).

So, by mentioning the Latin origin of the word habilis, Mauss (1973) associates dexterity with the classical definition of skill as technical proficiency (in Greek, tecknē means work of craftsperson, as Mauss (1973) himself emphasized in the quotation). Body dexterity corresponds, though, to functional adaptation to a skill, depicted as an objectified entity close to a tool, or more precisely to a technical object, once "body is man's first and more natural instrument" (Mauss, 1973, p. 75). The idea of a body as instrument or technical object reintroduces Mauss' (1973) theory within the separation between two dimensions of being: the objectivity of body and the subjectivity of psiqué that rules the body. This separation is in complete accordance with the Western concept of individual - a concept that Mauss himself and the functionalist sociology of early $20^{\text {th }}$ century have helped consolidate.

Such understanding may make us look at the body from inside out, as if the source that generates action is located inside of it and its materiality can be reduced to certain mechanical features. Surely the theories on movement have gone much further than Mauss (1973), as they include environmental influence over the body and also recognize an embodied power of agency. But divisions between what is in and out of the body - i.e. the mind and the world as separated entities - remain implicit in these studies. Mauss (1973) focused his analysis on daily body techniques such as sleeping, waking, walking, running, dancing, jumping, climbing, swimming, etc., and not on the domain of socially established professions. Nevertheless, it is no coincidence that formulations about movement and cognition have emerged in fields where the body is subject to the learning of a technique, such as dance (Desmond, 1997; Ness, 1992; Sheets-Johnstone, 1990), dramaturgy and performance (Jeudy, 2002; Solso, 1994).

This learning through the body is not explicitly related to professions, as the institutional basis of it is formal, i.e. cognitive learning. The core of modern professionalism is a kind of learning process that is strongly detached from practice, more centered in the mind than in the body, as well established professions cannot "simply [depend] on 'craft' factors in the learning of techniques and skills" (Jackson, 1970 , p. 4). Within the field of sociology of professions, the approach on the learning body has driven an emphasis on formal education as prerequisite for the constitution of professional identity (Rodrigues, 1998). In this field of research it is considered that one can reach the skill level of the working body through formal training in a work technique, modulated to fit an educational environment that has, of course, connections to the real environment of professional performance, but is but a simulation of it.

This field is also deeply concerned with the process of institutionalization of professions, namely division of work related to professional status and social arrangement of practices, in a way that formal professional education plays its role in tacitly indoctrinating bodies to perform a work practice or an occupation that may fit the needs of the structural dynamics of a capitalist system of production. This helps to explain why professionalization and work organization have been set apart from reflections about the body and, specially, why "the study of the body has tended to become estranged from the study of work just as analysis of organization has been abstracted from the body" (Hassard, Hollyday, $\&$ Willmott, 2000, p. 2). Within the field of OS, the issue of body and organization may be illustrated by a number of dimensions that abut a discussion about body, work performance and professionalization without directly approaching it. A good example comes from the study by Hindmarsh and Pilnick (2007) on the nature of embodiment in the workplace of teamwork in preoperative anesthesia. In exploring an alternative way of examining the body in OS, that study intended to show how competent organizational members display intercorporeal knowing, that is practical knowledge of the work they perform together. Even though the authors paid close attention to the normative notions of a medical team, they did not take the standpoint of considering the relations between the embodiment of work in the context of the normative/institutional directedness of medical professions. Other studies focusing on embodiment in the context of work teams and/or professional groups also turned attention to the importance of normative features as backbones for the learning processes that happens in the body and by it while 
people perform working practices together or in the same environment (Almeida \& Flores-Pereira, 2013; Llewellyn \& Hindmarsh, 2013; Mirchandani, 2015; Rosa \& Brito, 2010; Styhre, 2004; Tuncer, 2015; Yakhlef, 2010), but again without any specific interest in how work itself is linked to a network of embodied processes that ultimately shape professional identities and vice-versa.

Actually, even though the studies that we have just mentioned do not adhere to an institutional approach, the concept of professions - in the way that the field of OS has inherited from the field of sociology of professions - may be an obstacle for the flourishing of an embodied approach on professional identities. It is a common point in OS the understanding that more so than other types of social actors, the professionals in modern society have assumed leading roles in the creation and tending of institutions, as well as certain pattern of behaviors. This supports the assumption that professions are directly linked to institutional agents that may attempt to create general cultural-cognitive frameworks; or to devise normative prescriptions to guide behavior; and to still exercise coercive authority (Scott, 2008), thereby substantiating the idea of professional identity according to a structural-normative paradigm.

On the other hand, studies that emphasize the perception experience as originating from corporeally embodied pre-reflexive knowledge seek to understand embodiment of knowledge over and above the duality of what is in and out of the body. These studies advocate the phenomenological perspective of living-in-the-world, which means taking body (indistinctly mind and flesh) in complementarity and continuity. According to Ingold (2000), for example, we could refer to an embodied mind as much as to an enminded body, because both are entwined. Such an understanding about the body also brings a new light on perception within the field of OS. For example, the work of Sandberg and Dall'Alba (2009) take the entwinement of mind and body as a reflexive standpoint to understand how practice is constituted, and to explore the role of the body in the performance of organizational phenomena. Similarly, by utilizing the practical approaches that do not regard knowledge as something possessed, but as part of a practical engagement with an organizational performance, scholars have advanced our understanding of how organizational knowledge is produced, learned, sustained, performed and developed through everyday work practices (Gherardi, 2006, 2009; Nicolini, Gherardi, \& Yanow, 2003; Sandberg \& Dall'Alba, 2009). Among the different definitions that are gathered together under the label of Practice-Based Studies (PBS), the body is central to those that explore practices "from within", "from the point of view of practitioners and the activity that is being performed, with its temporality and processuality, as well as the emergent and negotiated order of the action being done" (Gherardi, 2009, p. 117). From this definition it follows that knowing is a situated activity that relies on the body and that knowing in practice is always a practical accomplishment (Gherardi, 2009).

With this definition in mind, we shall now turn to the subject of how the immediate experience of perception is deeply influenced by embodied social structures that are part of the world that we live in (Csordas, 1990). By doing that, we will take one more step to elaborate the way through which those experiences relate to the formation of self and professional identity.

\section{Living Body and the Context of Practices}

Again, we resort to Ingold (2000) - who had articulated the embodied paradigm (Csordas, 1990) and phenomenology (Merleau-Ponty, 2012) - in order to understand how the presence of the live body in the world constitutes the person. Going way further, Ingold falls back upon psychology, via its ecological branch (Gibson, 1974) to outline a phenomenology of dwelling that could include practices of life in context. Ecology and holism are key references in Bateson (1987) and they are deepened by Ingold (2000), along with Merleau-Ponty's (2012) influence. According to Ingold (2000), ecology of life should deal with the dynamics of organism plus environment as a whole, with no distinctions between body, conscience and context. 
Apart from revealing knowledge that is out there in the world, life is an ongoing process in which "Every living being, then, emerges as a particular, positioned embodiment of this generative potential" (Ingold, 2000, p. 51). That is the same of saying that experience with or in the environment supplies formation of conscience of the organism-person about him/herself, his/her attitudes and orientations regarding the world. It means that experience cannot be taken as a mediator between mind and nature, since both domains are not separated (Bateson, 1987). Instead, experience should be taken as intrinsic to the ongoing process of being alive in the world, or to the whole involvement of organism-person with environment. Experience though is about ontology of engagement.

Now, taking the metaphor of craft, and the concept of mastery as reflexive issues, we acknowledge that since the main feature of the craftsperson is the practical domain and the fine execution of the objects that he/she aims to create (Dormer, 1994; Sennett, 2008), it is no longer possible to describe it without understanding the way he/she interacts with the world. Within the field of management, Fischer (2012) put forward a definition of mastery as the dominance of a field of knowledge and practice. In other words, it entangles a conceptual and practical structure, i.e. a field that is ordered by its own structure of practical knowledge. Such structure is culturally given and comes into being through rites of passage that ensures its maintenance and renovation. So, the description of ability that reaches the concept of mastery that we have just mentioned suggests that the context also has a crucial importance, as it is the basis for the practice and the space/place for raising knowledge about such practice.

In putting perception under this light, we can cite Merleau-Ponty (2012) when stating that the world can never be separated from the person who perceives it, as every perception is a communication or a communion that enables the mating, meaning a deep and almost sexual fusion, of our bodies with things. As this mating forms us as persons, it also forms the environment that gets permanently changed after our presence. So the world is the ambiance where the entwinement of persons and things originates practices of living. This entwinement is a symbiosis, but not a fusion, which is the same as saying that the person could not live without the world, but both could actually be described with certain independence from one another.

Such assertion about perception leads us to deny the idea that the process of knowledge embodiment could be described as acquisition. Understanding this process takes restoring the human organism in the original context of engagement with its surroundings. When talking about achieving the level of skill - in fact, the subject of this article - this way of defining the learning process reverberates in social ways of transmitting a practical know-how. Traditional models for analyzing social learning processes tend to separate the process of transmission of embodied knowledge in two phases: first, it takes attention to see and understand a particular technique; then it takes turning this initial attention in a kind of mental map to perform the technique. So before practicing, "a generative schema or program is established in the novice's mind from his ( sic) observations of the movements of already accomplished practitioners" (Ingold, 2000, p. 353). And after acquiring it, "the novice imitates these movements by running off exemplars of the technique in question from the schema" (Ingold, 2000, p. $353)$.

It is undeniable that learning a skill involves observation and imitation, to put it in simple terms, but it is questionable that observation should be taken as a mental process as much as a perceptual one, because it leads to metaphors, mental images of real perception. The same happens to imitation, that could end up being a representation of practices, as if the practitioner was performing a social role. The idea of practical engagement with the world implies observation and imitation, when seeing and perceiving the work of a master enables the apprentice to experience the perceptual engagement with the environment. The key to observation and imitation, though, is when the apprentice reaches the conscience of his/her own body and of the world that involves it while observing and imitating. Undertaking practice and guided by his/her observations, the apprentice captures the sensation that things may have to him/her, which means that this person "learns to fine-tune his own movements so as to achieve the rhythmic fluency of the accomplished practitioner" (Ingold, 2000, p. 353). 
In summary, Ingold (2000) lists five critical dimensions of any kind of skilled practice with reference to the body. First, intentionality and functionality are immanent in the practice itself, rather than being prior properties, respectively, of an agent and an instrument. Secondly, skill is not an attribute of the individual body in isolation but of the whole system of relations constituted by the presence of the artisan in his or her environment. Thirdly, rather than representing the mere application of mechanical force, skill involves qualities of care, judgment and dexterity. Fourthly, it is not through the transmission of a formula that skills are passed from generation to generation, but through practical, hands on experience. Finally, skilled workmanship serves not to execute a pre-existing design, but actually to generate the forms of artefacts.

What needs to be highlighted, though, is that observation and imitation are part of the relation between the apprentice and his/her surroundings. Such relation has a social dimension, as it is supposed to happen among a community of practice or through the dialogical contact with the master. In both cases, the practitioner is not a self-constrained individual, rather the opposite. Elaborations on practice are not kept in his/her mind, but they are forged via social contacts that surely are part of the environment. So the temper of the practitioner is also something that rises from outside to inside, and not the opposite. Nevertheless, observation and imitation are part of a broader idea of embodied attention that have an after-effect on personality and identity. The apprentice becomes an expert not because he/she pays attention to play-acting of practical knowledge, but because he/she can decline to use such kinds of objectified stunts that equal acquisition of knowledge.

About learning through imitation, which means perceiving, understanding and performing in a practical way, it is worth noting that even though they are performing similar social roles, master and apprentice are different persons and the process of learning and transmitting knowledge between them entangles conflicts and contradictions, as perceptions and abilities derive from personal experiences. It means perceptions and abilities are social productions in dispute and the content and the cultural meaning of the practical knowledge are under the judgment of what to reproduce, how, for what reason, and to the behalf of whom. Such processes occur based on social struggles that manifest on and through the body, and that may reproduce the traditional structure of craft practice - as a cultural asset - while it may change it according to embodied social features of the practitioners (Bourdieu, 2000). It also highlights the evidence that the body is a social, historical construction that carries on disputes in itself because it is a political agent (Foucault, 2009), as in discussions of gender and race.

This way of learning corresponds to what Lave (1997) have called understanding in practice, as opposite to a culture of acquisition - the last one referring to learning theories that have been privileged for a long time by cognitive sciences and western educational institutions. Learning as acquisition, which implies mentally internalizing knowledge under the representational rules and schemas, is something detached from practice. Differently, understanding in practice is a process in which knowing is inseparable from doing and continuity between both actions is a pre-reflexive process of engagement with the world. In accordance with this theory of knowledge, such embodied know-how is the most powerful way of knowing, because the person him/herself becomes the knowledge that have been learned (Lave, 1997).

\section{Discussion}

\section{Practical space of the body and processional identity that rises from practice}

Even though discussions undertaken in this article may be too theoretical and even quite abstract to fit reality of work in organizations, we consider it relevant because few previous works have attempted to understand professional identity from the standpoint of an embodied paradigm within OS. The issues of identity related to the body have especially emerged in gender and diversity studies (Christie, 2006; Gherardi \& Poggio, 2001; Martin, 2001, 2003) and in studies that seek to analyze disciplinary power relations within organizational dynamics (Collinson, 2003; Fleming \& Spicer, 2003; Flores-Pereira, Davel, \& Cavedon, 2008; Hodgson, 2005). Albeit these are invaluable contributions to the study of body 
and embodiment on organizations, its emphasis on power relations and on the idea that bodies are shaped and produced in order to be efficient, regulated and docile sometimes blurs the analysis of transformation processes of the body from a phenomenological standpoint.

By that, the becoming of the body itself is kept under interpretative analysis of social-political context where those transformations occur. Recognizing how relevant the objectives and motivations of researchers that have taken those paths are, it is worth mentioning that studies on embodiment are in need of methodological tools that could enable the investigation of movements, sensations, perceptions and changes of the living body. Maybe that is why approaches that seek to explain bodies from the perspective of gender, diversity and power relations are more common, as they can rely on representations and mental elaborations about the object under study.

We do not want to deny or diminish the idea that the body is - practically as much as theoretically - a political matter (Foucault, 2009). But our effort in this paper embraces the centrality of corporeal experience to explain the developing of knowledge, self and identity. The phenomenological approach, as well as the embodiment paradigm that tags along with it, seek to oust the body from its usual objectified condition and to privilege experience as the starting point for knowing the world. Which means that we should try to capture experience in its immediacy, as it is a legitimate way for capturing reality and producing knowledge about it. Cultural issues regarding politics of and with the body are implicit to a phenomenological approach, as it assumes that experience is always backed by culture, once it can be pre-objective but never pre-cultural (Merleau-Ponty, 2012). Yet, the fact that such political issues shape perception is important to distinguish the experiences that result from the immediate contact of the body and the world, as well as to qualify the person that experiences it. Both assertions can be taken as important guidelines for methodological concerns on the study of embodiment processes, admitting that political issues are not crucial for capturing experience but for interpreting and explaining it.

Taking political discussions about the body under consideration, we observe that a small but relatively diverse group of studies are emerging in the field of OS. These studies tend to talk about the becoming of body within organizational context, mentioning identity more or less clearly as a subjective instance that rises from socio-material arrangement of work (Barzin, 2013; Parolin \& Mazzotti, 2013; Viteritti, 2013). These studies seek to problematize professional identity as a product of knowledge and skill embodiment, while they attempt to describe it as a process. The discussions that each of them undertake deserve to be briefly detailed here.

First it is worth mentioning Parolin and Mazzotti's (2013) work. Even though it does cite the word identity, this concept is clearly identifiable in the description of the two craftsmen whose workplaces and work practices are taken as empirical objects of the study. Based on Actor-Network Theory, those authors propose a model to describe knowledge that is put into practice - working knowledge, as they call - in the bodily interaction or worker and workplace. Parolin and Mazzotti (2013) highlight the importance of social-material arrangements for the building of knowledge that emerges from selective translations and they indeed dedicate a whole section of their article to theorize about education of the senses through professional practices. They state that professional practical knowledge is learned through process of situated learning and it is distributed equally between human beings, artifacts and material and linguistic systems of classification under use in the workplace. Although emphasizing the social dimension, as they reaffirm the importance of communities of practice for professional learning, Parolin and Mazzotti (2013) do not intend to develop an analysis of subjective processes that undertake the embodiment of professional knowledge and they also allude to professional learning as part of the identity formation process.

Similarly, Viteritti (2013) also develops analysis of knowledge for a professional group of scientists but not giving much importance to identity issues among them. The author investigates three episodes of knowledge embodiment by scientists in their laboratories, seeking to describe how body achieves mastery in laboratory practices. While not developing the concept of mastery, Viteritti (2013) uses it to explain the degrees of selective skill and professional competence that are necessary to the laboratory practices. Through the presented cases, Viteritti (2013) concludes that learned and embodied 
practices are produced by gradual efforts of the body in the course of actions, through daily immersion in the social-material environment of the practical learning.

In Barzin's (2013) study, worker's gestures are understood as recursive patterns and routines of body movement. Three instances of corporeality - technical, aesthetical and embodiment - are taken as generative elements of organizational gestures. According to empirical research findings conducted between workers organized in a production line, professional and personal identity merge with embodiment when technique is perfectly mastered and transforms itself in elegance in executing movements. For this author, in a certain point during the process of embodiment of working gestures, mastering merges technique and aesthetic aspects of gestures and work tools so deeply in the corporeality of the practitioner, that techniques, gestures and tools altogether become part of his/her body. Elegance appears, though, for the external observer of the gesture and it looks absolutely spontaneous, as the execution of complex body movements was easy to achieve. Elegance in the gesture is an identity trait of the practitioner, as it is original and carries the signature that makes the unique style of one person recognizable.

Each of the three studies that we just mentioned seek to clarify how embodiment processes of knowledge/skill are related to what we tried to define as mastery. In all of them, we can notice that the notion of mastery is central to characterize the way through which practical relation with knowledge transforms the body - that is indistinctively both object and subject of action. In this sense, reaching the skill level that characterizes mastery implies deep changes - in the body, as much as in the self - that reflects on the very being. Within OS, the mentioned works are relevant, especially when we discuss them side by side with theoretical articulations that we have developed in this article, because they enable the study of professional identity from an embodied dimension (Barzin, 2013). They also propitiate the analyses of social-material arrangements that are part of the skill embodiment process (Parolin \& Mazzotti, 2013; Viteritti, 2013) and that are inseparable from it, as we have stated in this article, resorting to a holistic phenomenological perspective (Ingold, 2000; Merleau-Ponty, 2012).

\section{Methodological issues in the study of embodied knowledge}

Besides this theoretical gap, we also want to address the need to discuss different paths that may guide empirical studies about body changing processes under craftsmanship and mastery. Taking the phenomenological perspective of Merleau-Ponty (2012), we suggest that the focus of analysis should be the practical space of the body, in order to grasp the understanding of fundamental relations between body and space. As we have said before, Merleau-Ponty (2012) talks about the movement of being in the world and how situations that bring up body movements are not entirely articulated, i.e. its meaning is not entirely recognizable. Such operations are lived as open situations that invite experimentation and bodily recognition to provide practical meanings to the things of the world. These are the kind of knowledge relations that the body is able to face in a reflective way. About this, it is important to state that reflective movements open up the meaning of a situation as they are driven to objects, while perception itself is the intention of meaning that relies on pre-objective view of what we call being-inthe-world.

While discussing spatiality of body, Merleau-Ponty (2012) highlights that the borders of the body are a frontier through which ordinary spatial relations overcome themselves. It happens because parts of the body and of space get intertwined in each other in an original way, as they get mixed and juxtaposed. Thus, in what concerns spatiality, body is something else that is not exactly a figure, nor the background. Every figure lines up under the double horizon of exterior space and bodily space, and both are forming the practical system of the body plus environment.

In this sense, Merleau-Ponty (2012) proposes that we recover the associationist notion of body schema. Body schema sets up a global conscience of one's posture in the sensorial world. It is not the conscience about existing parts of the body, but its whole integration and its engagement in the project of life or organisms. Body schema is dynamic and it brings to light a new kind of existence that is also circumstantial and deeply oriented towards bodily responses to environment changes. Still according to 
Merleau-Ponty (2012), the idea of body schema is a way of grasping meaning from practical action, making every single movement of the body acquire a sense related to the very aim of the body in performing those actions. In this way, body schema is a way of expressing that the body actively exists in the world.

Thus, spatiality of the body is not a spatiality of position, but rather a spatiality of situation, which designates the anchorage of the active body as an object, in face of practical activities. Such anchorage comprises a rich comprehension of the environment where practices take place (Ingold, 2000) and it may compel restituting social conflict issues regarding embodiment processes as a way to understand how the body is, simultaneously, subject of perception and object in the context. It also allows to discern how both positions are entwined and feed one another, as ways of perceiving are coupled with the possibilities of experiencing aspects of the world that are cultural, social and historical. To apprehend and understand practical activities, though, we need to again draw borders between body and the world in order to track directions, to establish lines of power and elaborate perspectives. Summing up, it is necessary to reorganize those limits according to projects and objectives, relations of neighborhood and familiarity, in order to understand how the inner activity of the body transcends to the environment. It is also necessary to invert the natural relation between body and surrounding so we can understand human work as part of thickness of being (Merleau-Ponty, 2012).

Body appears simultaneously as a posture and as an object, which opens up different possibilities for research. By this we are saying that research on embodiment of skills should try to understand and depict body schemas and it's surroundings in relation to each other. The main challenge for research on this issue is that we need to catch the meaning of action and transcript it to a general comprehension, so the unspeakable features of experience have to gain an objectified and even representational dimension. A way to do it may be via Actor-Network Theory, as Parolin and Mazzotti (2013) have demonstrated. Another could be through ethnographic research, when the researcher him/herself experiments this relation in his/her own body.

About that, we could mention the study of Almeida and Flores-Pereira (2013) on the work of ballet dancers in a dance company. Based on ethnographic research, this article describes in a very accurate way how the identity of professional ballet dancers is inscribed in people's bodies while they train and perform for the dance company. With a view to investigate the embodiment of ballet dancers' work, one of the authors of the study engaged in a professional ballet company using her own embodied resources to observe how ballet dancers experience space, time, weight and strength, as well as how they sense body capacities, in a kinesthesic way. Almeida and Flores-Pereira (2013) call their research approach "embodied ethnography" (p. 727), in an attempt to differentiate and to give a special qualification to the way researchers should use their body, senses and emotions as methodological sources to get an embodied (Flores-Pereira et al., 2008; Hindmarsh \& Pilnick, 2007; Sinclair, 2005) and emplaced (Pink, 2011) comprehension of field data. The concept of emplacement, which is particularly important for Almeida and Flores-Pereira's (2013) study, ascribes the multisensoriality entangled in the relation researcher/researched in the environment, taking a social, cultural and historical dimension of it.

Even if Almeida and Flores-Pereira (2013) do not intend to situate issues related to identity/corporeality in the social-material arrangement of work within organizations, their work shows processes of embodiment of discipline and hierarchy of power of the dance world, as one of the authors joined the company for six months (it is worth mentioning she had previous experience in professional dance). In the data analysis, the authors reach conclusions that approach the previous findings of another ethnography of the body, conducted in the cultural field of professional ballet by Wainwright and Turner (2004a), for enabling the understanding of the balletic body as a series of cultural practices. In methodological terms, Wainwright and Turner (2004a) use ethnography to challenge the disembodied literatures on dance, specifically on ballet, that tend to adopt a post-modern reading of dance as text (Adshead-Lansdale, 1999; Desmond, 1997; Goellner \& Murphy, 1995; Wainwright \& Turner, 2004b). In theoretical terms, the authors assert that ballet is a social practice whose embodiment's process is related to distinctions in the ballet habitus that unfolds in three dimensions: an individual one, an institutional one and a choreographic one. By taking the concept of habitus of Pierre Bourdieu (1984 as cited in Wainwright \& Turner, 2004a) as a fruitful approach to both theory and research on the body, 
Wainwright and Turner (2004a) link body and professional identity in accordance with a post-structural perspective that broaches previous discussion about sociology of professions, as they eventually focused on professional identity as an embodied process that expresses the interrelationship between individuals and institutions, body and society.

Almeida and Flores-Pereira (2013), in their turn, center their attention in how ballet identity is embodied through pain and extreme technical demand and also how aging and physical changes of the ballet dancer's body is a threat to a dancer's identity. From a methodological point of view, what is new about their work is the use of non-representational ethnography for researching ballet dancers as professionals that depend on their bodies to work just like any other professional class. The choice of ballet dancer's work as research field substantiates what Chandler $(2012$, p. 865) has called "the use of dance analogy as heuristic device in ethnographies of work". Ballet dancers were chosen by Almeida and Flores-Pereira (2013) as obvious examples of the embodiment of professional identity, but such an embodiment process could be investigated in any profession, even those that seem more mental than physical, such as the work of an accountant for example. Nevertheless, the nature and variety of dance can be explored as a way of studying movement, gendered embodiment, audience, emotion and rhythm at work (Chandler, 2012). In theoretical terms, the main contribution of this paper is the way it relates those embodiment processes to the social-cultural and historical background of battle practices and the organizational culture of ballet companies. Again, the institutional context of ballet professional practice is the background for the understanding of the embodiment process of professional identity. While such an approach has much in common with classic studies of work, i.e. sociology of professions, its ethnographical approach also unsettle some of the dominant ways of researching work and its organization.

\section{Conclusion}

In this article, we choose to make an analogy with craft to elaborate a contribution to the embodiment studies in OS. As Wainwright and Turner (2004a), Chandler (2012) and Almeida and Flores-Pereira (2013) have taken dance as a useful heurism to study work from a practical and embodied perspective, we assumed that the concept of mastery could be particularly useful to guide studies on transformation processes of the body. As cognition that emerges from practice in a polished, sophisticated and beautiful way, mastery highlights not only embodied processes, but also the social organization of knowledge entangled through practice and the singular configuration of factors that help build work identities. It goes beyond the social division of labor, even though it can reinforce it. Thus, the theoretical contribution of this paper is to reinforce the concept of mastery as a specific way of understanding skill, one that results from knowledge embodiment and that changes the whole person. It also highlights a way of understanding work identity as an embodied matter, countering the tendency to explore such topic from a structural-functionalist viewpoint. Accordingly, the originality of this contribution relies on the theoretical background that we have chosen to support it, which is the embodiment paradigm and the philosophic viewpoint of phenomenology. By doing this, we also contribute to the debates around and about the limits of body and self within OS, taking a practical standpoint. The concept of mastery, which comes from the metaphor of craft, also situates this paper in a post-modern or a non-modern perspective on the study of learning through practice in OS.

In methodological terms, the concept of mastery may embrace some unspeakable aspects of the knowledge embodiment process, serving as a representational source for researchers that investigate working practices from a phenomenological standpoint that aims to explain inexpressible features of know-how. Understanding, for example, that mastery is related to elegance in gestures of the skilled worker (Barzin, 2013), allows us to elaborate aesthetic parameters to understand and to explain the nature of work that is made by the person that becomes a master in his/her professional field. Analogously, paying attention to social-material and, also, historical dimensions of certain practices is something that needs to be done in order to explain the richly structured environment (Ingold, 2000) where practices take place. Findings that came from theoretical reflections launched in this paper should 
be supported by empirical research. It is also worth mentioning that the concept of mastery and the analogies with craft that have framed the undertaken reflections are non-modern and, as such, quite distant from the organization of work in the contemporary capitalistic world. It would be necessary to take it as a metaphor for contemporary work, with the abstractions and adaptations that this may imply. We conclude this article asserting the importance to understand the body as a whole of subject-object and likewise that it is necessary to place the body in the environment in order to understand practical learning process.

\section{References}

Adamson, G. (2007). Thinking through craft. New York: Berg.

Adshead-Lansdale, J. (Ed.). (1999). Dancing texts: intertextuality in interpretation. London: Dance Books.

Almeida, D. D., \& Flores-Pereira, M. T. (2013). As corporalidades do trabalho bailarino: entre a exigência extrema e o dançar com a alma. Revista de Administração Contemporânea, 17(6), 720738. Retrieved from http://www.scielo.br/pdf/rac/v17n6/a06v17n6.pdf. doi: 10.1590/S141565552013000600006

Barzin, Y. (2013). Understanding organisational gestures: technique, aesthetics and embodiment. Scandinavian Journal of Management, 29(4), 337-393. doi: 10.1016/j.scaman.2013.09.003

Bateson, G. (1987). Steps to an ecology of mind: collected essays in anthopology, psychiatry, evolution and epistemology. San Francisco, Scranton, London \& Toronto: Chandler.

Becker, H. (1978). Arts and crafts. American Journal of Sociology, 83(4), 862-889. Retrieved from http://www.jstor.org/stable/2777719

Bourdieu, P. (2000). Pascalian meditations. Stanford: Stanford University Press.

Chandler, J. (2012). Work as dance. Organization, 16(6), 865-878. doi: 10.1177/1350508411433669

Christie, A. (2006). Negotiating the uncomfortable intersections between gender and professional identities in social work. Critical Social Policy, 26(2), 390-411. doi: 10.1177/0261018306062591

Collinson, D. L. (2003). Identities and insecurities: selves at work. Organization, 10(3), 527-548. doi: $10.1177 / 13505084030103010$

Csordas, T. J. (1990). Embodiment as a paradigm to anthropology. Ethos, 18(1), 5-47. doi: 10.1525/eth.1990.18.1.02a00010

Desmond, J. C. (1997). Meaning in motion: new cultural studies of dance. New York: Duke University Press.

Dormer, P. (1994). The art of the maker. London: Thames and Hudson.

Fischer, T. (2012). Apresentação. In T. Fischer \& M. R. Soares, Catálogo dos mestres em artes e ofícios populares do território do Sisal/Bahia (pp. 7-9). Salvador, Brasil: UFBA.

Fleming, P., \& Spicer, A. (2003). Working at a cynical distance: implications for power, subjectivity and resistance. Organization, 10(1), 157-179. doi: 10.1177/1350508403010001376

Flores-Pereira, M. T., Davel, E., \& Cavedon, N. R. (2008). Drinking beer and understanding organizational culture embodiment. Human Relations, 61(7), 1007-1026. doi: $10.1177 / 0018726708093906$ 
Foucault, M. (2009). História da sexualidade: a vontade de saber. São Paulo: Graal.

Gherardi, S. (2006). Organizational knowledge: the texture of workplace learning. Oxford: Blackwell.

Gherardi, S. (2009). Introduction: the critical power of the practice lens. Management Learning, 40(2), 115-128. doi: 10.1177/1350507608101225

Gherardi, S., \& Poggio, B. (2001). Creating and recreating gender order in organizations. Journal of World Business, 36(3), 245-259. doi: 10.1016/S1090-9516(01)00054-2

Gibson, J. J. (1974). The perception of the visual world. Westport: Greenwood Press.

Goellner, E., \& Murphy, J. (Eds.). (1995). Bodies of the text: dance as theory, literature as dance. New Brunswick: Rutgers University Press.

Greiner, C. (2008). O corpo: pistas para estudos indisciplinares. São Paulo: Annablume.

Hancock, P. (2008). Embodied generosity and ethics of organization. Organization Studies, 29(10), 1357-1379. doi: 10.1177/0170840608093545

Hassard, J., Holliday, R., \& Willmott, H. (Orgs.). (2000). Body and organization. London: Sage.

Hindmarsh, J., \& Pilnick, A. (2007). Knowing bodies at work: embodiment and ephemeral teamwork in anaesthesia. Organization Studies, 28(9), 1395-1416. doi: 10.1177/0170840607068258

Hodgson, D. (2005). 'Putting on a professional performance': performativity, subversion and project management. Organization, 12(1), 51-68. doi: 10.1177/1350508405048576

Ingold, T. (2000). Perceptions of environment: essays on livelihood, dwelling and skill. London \& New York: Routledge.

Jackson, J. A. (1970). Professions and professionalization. Cambridge: Cambridge University Press.

Jeudy, H. P. (2002). O corpo como objeto de arte. São Paulo: Estação Liberdade.

Klegon, D. (1978). The sociology of professions: an emerging perspective. Work and Organization, 5(3), 259-283. doi: 10.1177/073088847800500301

Kleinman, A., \& Kleinman, J. (1991). Suffering and its professional transformation: toward an ethnography of interpersonal experience. Culture, Medicine and Psychiatry, 15(3), 257-275. doi: 10.1007/BF00046540

Lakoff, G., \& Johnson, M. (1980). Metaphors we live by. Chicago: University of Chicago Press.

Lakoff, G., \& Johnson, M. (1999). Philosophy in the flesh: the embodied mind and its challenge to Western thought. New York: Basic Books.

Larson, M. S. (1977). The rise of professionalism: a sociological analysis. Berkeley: University of California Press.

Lave, J. (1997). The culture of acquisition and the practice of understanding. In D. Kirshner \& J. A. Whitson (Eds.), Situated cognition: social, semiotic, and psychological perspectives (pp. 17-36). Mahwah, NJ: Lawrence Erlbaum Associated.

Llewellyn, N., \& Hindmarsh, J. (2013). The order problem: interference and interaction in interactive service work. Human Relations, 66(11), 1401-1426. doi: 10.1177/0018726713479622

Llinás, R. (2002). I of the vortex: from neurons to self. London: Bradford Books. 
Martin, P. Y. (2001). Mobilizing masculinities: women's experiences of men at work. Organization, 8(4), 587-618. doi: 10.1177/135050840184003

Martin, P. Y. (2003). 'Said and done' versus 'saying and doing': gendering practices, practicing gender at work. Gender and Society, 17(3), 342-366. doi: 10.1177/0891243203017003002

Mauss, M. (1973). Techniques of the body. Economy and society, 2(1), 70-88. doi: $10.1080 / 03085147300000003$

Merleau-Ponty, M. (2012). Phenomenology of perception. New York, NY: Routledge.

Mirchandani, K. (2015). Flesh in voice: the no-touch embodiment of transnational customer service workers. Organization, 22(6), 909-923. doi: 10.1177/1350508414527779

Ness, A. (1992). Body, movement and culture: kinesthetic and visual symbolism in Philippine community. Pennsylvania: University of Pennsylvania Press.

Nicolini, D., Gherardi, S., \& Yanow, D. (2003). Knowing in organizations: a practice-based approach. Armonk: M. E. Sharpe.

Parolin, L. L., \& Mazzotti, A. (2013). Sensitive translations: sensitive dimension and knowledge within two craftsmen's workplaces. Scandinavian Journal of Management, 29(4), 353-366. doi: 10.1016/j.scaman.2013.07.003

Parsons, T. (1939). The professions and social structure. Indianapolis: Bobbs Merrill.

Pink, S. (2011). From embodiment to emplacement: re-thinking competing bodies, senses and spatialities. Sport, Education and Society, 16(3), 343-355. doi: 10.1080/13573322.2011.565965

Reed, S. A. (1998). The politics and poetics of dance. Annual Review of Anthropology, 27, 503-532. doi: 10.1146/annurev.anthro.27.1.503

Risatti, H. (2007). A theory of craft: function and aesthetic expression. Chapel Hill: The University of North Carolina Press.

Rodrigues, M. L. (1998). Sociologia das profissões. Oeiras: Celta Editora.

Rosa, A. R., \& Brito, M. J. de (2010). "Corpo e alma" nas organizações: um estudo sobre dominação e construção social dos corpos na organização militar. Revista de Administração Contemporânea, 14(2), 194-211. Retrieved from http://www.scielo.br/pdf/rac/v14n2/v14n2a02.pdf. doi: $10.1590 / \mathrm{S} 1415-65552010000200002$

Sandberg, J., \& Dall'Alba, G. (2009). Returning to practice anew: a life-world perspective. Organization Studies, 30(12), 1349-1368. doi: 10.1177/0170840609349872

Scott, W. R. (2008). Lords of dance: professionals as institutional agents. Organization Studies, 29(2), 219-238. doi: 10.1177/0170840607088151

Sennett, R. (2008). The craftsman. New Haven and London: Yale University Press.

Sklar, D. (1994). Can bodylore be brought to its senses? The Journal of American Folklore, 107(423), 9-22. doi: $10.2307 / 541070$

Sheets-Johnstone, M. (1990). The roots of thinking. Philadelphia: Temple University Press.

Sinclair, A. (2005). Body and management pedagogy. Gender, Work and Organization, 12(1), 89-104. doi: 10.1111/j.1468-0432.2005.00264.x

Solso, R. (1994). Cognition and the visual arts. Cambridge: Bradford Books. 
Styhre, A. (2004). The (re)embodied organization: four perspectives on the body in organizations. Human Resource Development International, 7(1), 101-116. doi: $10.1080 / 1367886032000150578$

Tuncer, S. (2015). Walking away: an embodied resource to close informal encounters in offices. Journal of Pragmatics, 76, 101-116. doi: 10.1016/j.pragma.2014.11.012

Viteritti, A. (2013). It's the body (that does it)! The production of knowledge through body in scientific learning practice. Scandinavian Journal of Management, 29(4), 367-376. doi: 10.1016/j.scaman.2013.09.002

Wainwright, S. P., \& Turner, B. S. (2004a). Epiphanies of embodiment: injury, identity and the balletic body. Qualitative Research, 4(3), 311-337. doi: 10.1177/1468794104047232

Wainwright, S. P., \& Turner, B. S. (2004b). Narratives of embodiment: body, aging, and career in Royal Ballet dancers. In H. Thomas \& J. Ahmed (Eds.), Cultural bodies: ethnography and theory (Chap. 4, pp. 98-120). Oxford: Blackwell Publishing.

Yakhlef, A. (2010). The corporeality of practice-based learning. Organization Studies, 31(4), 409-430. doi: $10.1177 / 0170840609357384$

\section{Authors' Profiles}

Marina Dantas Figueiredo

Av. Washington Soares, 1321, 60811-905, Fortaleza, CE, Brazil. E-mail address: marina.dantas@ gmail.com

Ana Sílvia Rocha Ipiranga

Av. Abolição 2480/1004, Meireles, 60165-080, Fortaleza, CE, Brazil. E-mail address: anasilviaipi@uol.com.br 